\title{
The Exploration on Experiment Teaching System Design of Civil Engineering in Modern Distance Education
}

\author{
Liyan Zhao ${ }^{\mathrm{a}}$, Dan Tian ${ }^{\mathrm{b}}$ and Ping Dai ${ }^{\mathrm{c}}$ \\ School of Distance and Continuing Education, Dalian University of Technology, Dalian 116023, \\ China \\ anet13@dlut.edu.cn, bnetwork2@ dlut.edu.cn, cnet4@ dlut.edu.cn
}

\begin{abstract}
Experiment teaching is one of the most important parts of practice teaching link in higher education. With the improvement of practice teaching link on higher education teaching reform, the experiment teaching courses should be improved and paid more attention to. This paper summarizes the development patterns of experiment teaching courses in modern distance education. And it puts forward online experiment teaching system on civil engineering, based on the characters of distant education students.
\end{abstract}

Keywords: Modern distance education; online teaching; experiment teaching; teaching system design.

\section{The Importance of Experiment Teaching on Modern Distance Education}

Modern distance education is a new education pattern which developed basing on multimedia technology and network technique. Positioning in training applied talents, its teaching activities depend on both computer and network. The students are most on job. This kind of education is more autonomous, interactive, and personalized. It can satisfy the students on job by "learning anytime and anywhere, enjoying high quality learning resources, and getting equal chance on education as regular higher education” [1].

"Intensifying the practical teaching link" is an important part of higher education teaching reform. It reflects the teaching level of universities. Otherwise, experiment teaching is one of the most important parts of practical teaching link undoubtedly. It plays a significant role on training applied talents. Students can get the basic method, skills, and operational capacity on experiment courses. At the same time, their abilities on observation, getting information, and analysis are also improved. So at this field, it cannot be replaced by other teaching link. Although most distance education students come from work, their without systematic practice on job can't replace experiment courses [2, 3]. Take engineering majors for example, the students who work at the construction site rurally have some problems on practice. They may know the demands about the standard or regulation mechanically. But this knowledge may not be mastered deeply and systematically. So it is hard for them to get connection between theory and practice. This problem can be solved at a certain extent by experiment courses' training. What's more, engineering bases on experiment. Experiment teaching takes an important role on learning specialized knowledge.

\section{The Patterns of Online Experiment Teaching System in Modern Distance Education}

Different from regular higher education's experiment teaching, experiment teaching for distance education can't be operated in laboratory or on site. The experiment teaching should be showed on online learning platform by multimedia, computer and network technology. At present, the patterns of online experiment courses in modern distance education are demonstration experiment teaching system, remote laboratory control teaching system, and virtual simulation experiment teaching system.

Demonstration Experiment Teaching System. Demonstration experiment makes all the experimental process in laboratory into a video recording, and mixed other resources into an online courseware. The demonstration experiment teaching courseware contains explaining experiment purpose, content, process operation, demonstration experimental results, data processing methods.etc. 
The students can learn the courseware at online platform for the whole test. After that, they may complete test report by the information what they get in demonstration experiment courseware. At last, they should delivery the test reports at platform.

This teaching system has relatively low cost, short production period, precise and detailed experiment process, and prominent visual image. It can provide comprehensive and exact experimental experience as in laboratory. But this teaching system's drawback is the lack of students' hand-on experiments in the process. And the correct and exact process cannot make learners to find error in real tests. It is hard to train the students' ability to find and solve problems. But it can be widely used as important experiment resource in distance education at present.

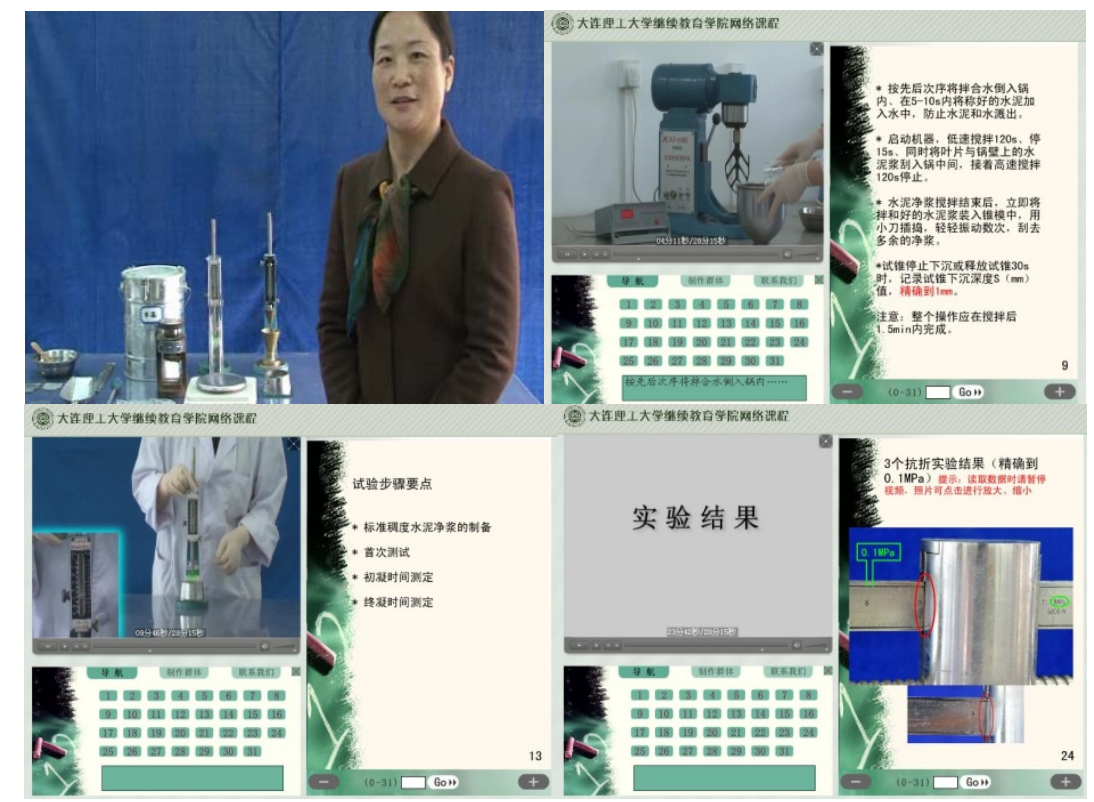

Fig. 1 Demonstration experiment of building material in Dalian University of Technology

Remote Laboratory Control Teaching System. Computer, multimedia, and communication technoligy is applied to remote laboratory control teaching system sufficiently. Equipments and control systemin laborotery are converted into image, sound, state, etc. And they are transfered to learners' computers by various media. The learners can control the equipments which are in remote laboratory by their computers. Then, the equipments' operation video and test results also can be sent to learners' computers[4].

This teaching system has some advatages. The experiments are real and controllable as same as in laborotary. It almost can get the same effect that students do in laborotary. But it also has some disadvatages. It has more requierments on sensors, actuators and network environment. Such as, the experimental instruments must be electrified and high controllability. The common online laborotary is difficult to achieve this standard. And one remote laborotaory contorl teaching system cannot simultaneously be connected by too much students. Each experiment course must build a number of remote laboratories to satisfiy so many online students. And it cost too much. At present, there are some universities establish and open up this system to their online students.

Virtual Simulation Experiment Teaching System. Virtual experiment environment is set up by computer with computer technology, simulation technology and mathematical modeling technology. And this system provides the exercisable virtual experiments which enable students to complete experiment online by human-computer interaction interface. And virtual simulation experiment teaching system can provide integrated management at online experiment teaching and learning [5].

This experiment system abstracts the complex real experimental devices and process into vivid and operable electronic experimental environment. Students can repeat virtual simulation experiment on computer. And it has good interface of human-computer interaction to achieve the similar effect as field experiments. Virtual simulation experiment can improve learners’ interest well. Its disadvantage 
is the test results are presupposed, lack of uncertainty in the real experiment. It is used in the online experiment of electrical engineering, mechanical engineering, computer and other engineering majors in distance education.

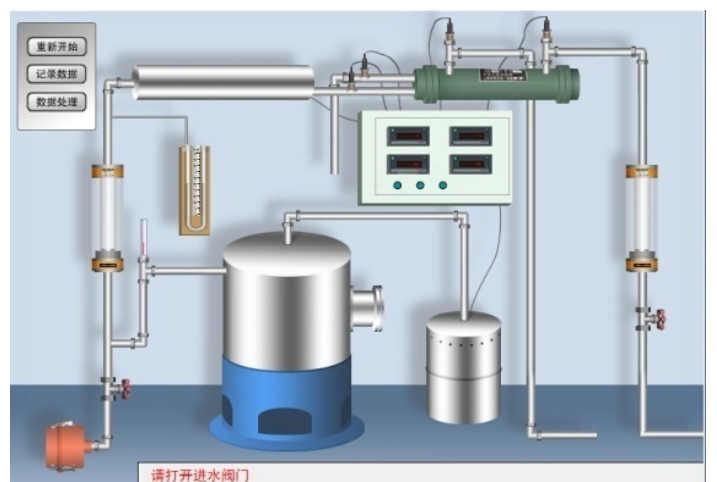

Fig. 2 Virtual simulation experiment of principles of chemical engineering in Jiangnan University

\section{Analysis of Experimental Types in Civil Engineering}

Civil engineering is a practical and applied engineering major. Its major courses are "Measurement”, "Building Materials", "Soil Mechanics and Foundation”, "Reinforced Concrete Structure”, "Steel Structure”, “Construction Technology”, etc. The experiments can be summarized to four types: skill operation, theoretical verification, professional design and comprehensive research. Skill operation-type experiments' aim is making students to master professional equipment-using skills. Such as, how to use measuring instruments. Theoretical verification-type experiments need students to verify the nature, phenomenon and characteristics by experimental operation. Professional design-type experiments need to be designed and calculated by students before experiment. Then, get right test results after operating and revising. Comprehensive research-type experiments are generally with the contents of several courses. This type experiments can train the ability of students to carry out scientific research. These professional experiments have the characteristics of practical, comprehensive and applicative, which have very big promotion effect on students' ability of connection between theory with practice, engineering application and innovation [6].

Table 1 Summary analysis on the types of civil engineering specialty experiment

\begin{tabular}{|c|c|c|}
\hline $\begin{array}{c}\text { Type of } \\
\text { experiment }\end{array}$ & $\begin{array}{l}\text { Content of experiment } \\
\text { example }\end{array}$ & Teaching demands \\
\hline $\begin{array}{c}\text { skill } \\
\text { operation-type }\end{array}$ & Measuring instruments using & Master basic skills and basic operations. \\
\hline $\begin{array}{l}\text { theoretical } \\
\text { verification-type }\end{array}$ & $\begin{array}{l}\text { Building material performance } \\
\text { test, concrere simply supported } \\
\text { beam experiment }\end{array}$ & $\begin{array}{l}\text { Master the experimental methods and the basic } \\
\text { theory knowledge, analyze the test results. }\end{array}$ \\
\hline $\begin{array}{l}\text { professional } \\
\text { design-type }\end{array}$ & $\begin{array}{c}\text { Design of mix proportion of } \\
\text { concrete }\end{array}$ & $\begin{array}{l}\text { On the basis of mastering theoretical } \\
\text { knowledge, complete the experimental design, } \\
\text { and verify , analyze the test results. }\end{array}$ \\
\hline $\begin{array}{l}\text { comprehensive } \\
\text { research-type }\end{array}$ & $\begin{array}{l}\text { Science and technology } \\
\text { competition }\end{array}$ & $\begin{array}{l}\text { Independently develop the reseach plan and } \\
\text { methods, carry out the practice operation and } \\
\text { adjustment, data collation and analysis, and } \\
\text { draw the test results and conclusions. }\end{array}$ \\
\hline
\end{tabular}

Universities can choose reasonable type and experimental content of experimental courses by characteristics of school types and students to meet the requirements of practical teaching. 


\section{The Exploration on Experiment Teaching System Design of Civil Engineering in Distance Education}

The purpose of distance education is citizen learning, life-long education, and adult education. At present, most experiment courses in distance education only copy the curriculum framework of regular higher education, change the difficulty and reduce content without considering features of teaching object [7]. The learners' vision and innovation ability can't be developed well. Facing the challenge of "Intensifying the practical teaching link", taking the characteristics of adult education as the starting point, it is necessary to reform experiment teaching link in distance education to enhance the students' experimental ability and innovation ability, and improve the quality of practical teaching. According to the characteristics of distance education students, design the experiment system of "reasonable content, diversified experiment patterns, and hierarchical teaching depth." Then based on the specialty of civil engineering, take an overall design of experimental course of distance education from the content, online experiment patterns, and assessment methods. As shown in figure 3.

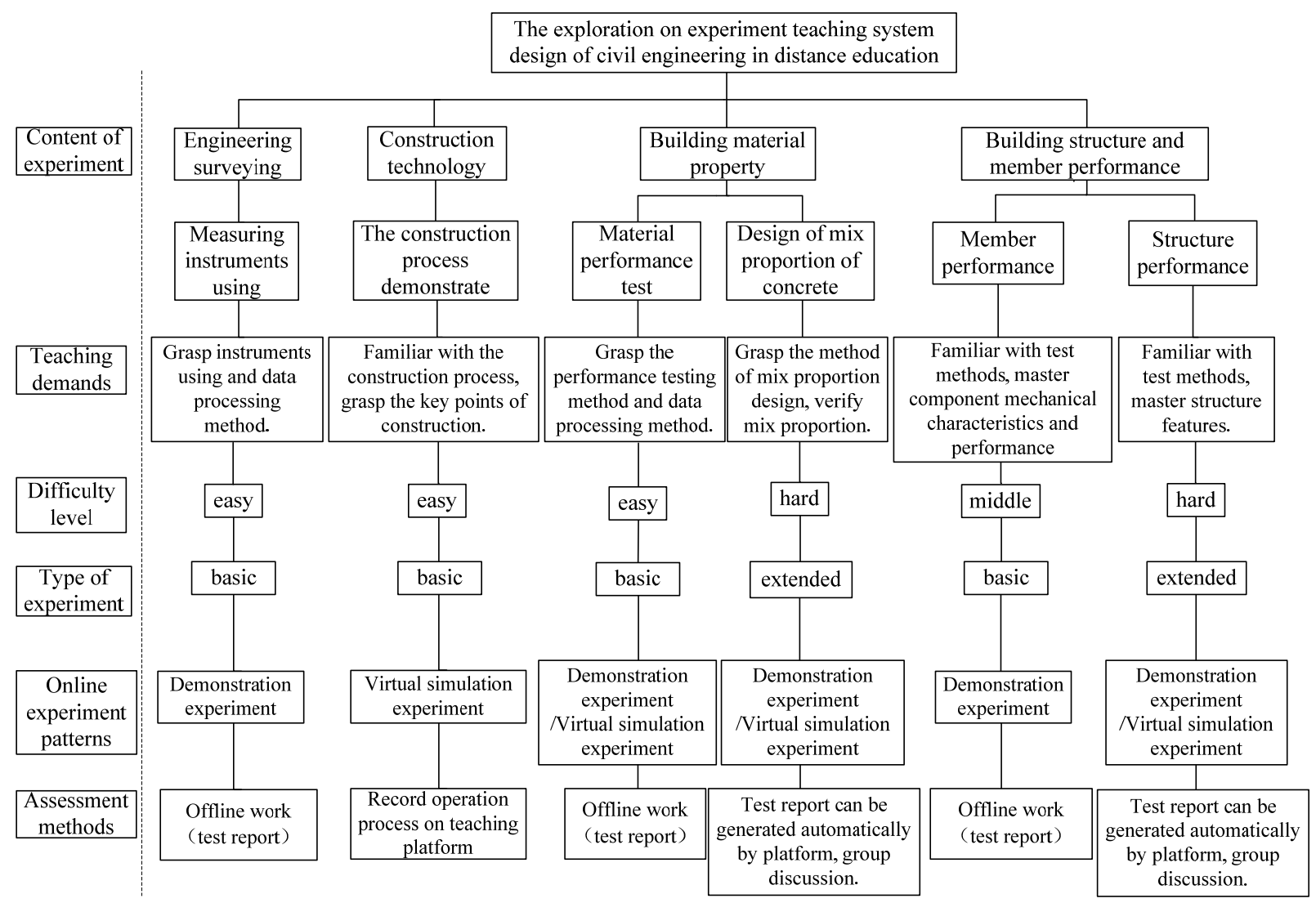

Fig. 3 The exploration on experiment teaching system design of civil engineering in distance education

(1) Content of experiment. Starting from the important knowledge of the core courses of civil engineering, the experiment would include engineering surveying, construction technology, building material property, and building structure performance experiment.

(2) Type of experiment. Skill operation-type and theoretical verification-type are necessary. As extended resource, professional design-type experiment will be needed to diversify experiment patterns, and enhance teaching depth to meet the needs of students at different knowledge level.

(3) Online experiment patterns. According to the different content and requirements of experimental teaching, both demonstration and virtual simulation experiments will be needed. For professional design experiments, the development of virtual simulation experiments can meet the requirements of experimental teaching better. 
(4) Assessment methods. For the assessment of different experiments, students can deliver offline report file, or the test report can be generated automatically by online platform. Especially for professional design-type experiment, which can be as an extended resource, automatically generate reports will be available. The operation process is more important than experiment results.

\section{Summary}

As an important part of practice teaching link in modern distance education, experiment teaching reflects teaching level of distance education. How to develop and design variety of high-quality experimental teaching resources which satisfy both characteristics of students and teaching requirements of experiment, proposes higher requirements to experiment system designers, the online experiment course developers and experiment teachers. Excellent design of online experiment teaching system resources can not only make distance education students to grasp professional knowledge, experimental skills, but also improve students' learning interest and promote the cultivation of innovation.

\section{References}

[1] Liyan Zhao, Ping Dai, Analysis on the construction of online course for civil engineering, Journal of Dalian University of Technology(Social science edition). 6 (2011) 69-70.

[2] Zheng $\mathrm{Xu}$, The discussion of the experiment teaching in distance education. Journal of Tianzhong, 2(2013)115-116.

[3] Lin Yang, The discussion of the experiment teaching mode in distance education. China Science and technology imformation. 7 (2012) 227.

[4] Weidong Lan, Development of teaching system of the science and engineering experiment course in the local learning center of Distance Education, Journal of Guangxi Commercial College. 3 (2003) 96-98.

[5] Chunhong song, Liyan Zhao, Development of network courseware for building materials participating in demonstration experiment, Modern education technology 22 (2012) 116-119.

[6] Tingting Zhang, Baomin Wang, Lichun Ren, Xin Gao, Experimental teaching methods of civil engineering specialty oriented to the excellence engineer, Experiment technology and management. 32 (2015) 189-191.

[7] Haiming Jiang, Yongqiang Dai, The reform and innovation of the internet education model of adult education chemistry experiment under the background of lifelong learning, Journal of Hunan University of Science and Engineering. 36 (2015) 73-75. 